International Journal of Current Advanced Research

ISSN: O: 2319-6475, ISSN: P: 2319 - 6505, Impact Factor: SJIF: 5.995

Available Online at www.journalijcar.org

Volume 6; Issue 5; May 2017; Page No. 3570-3573

DOI: http://dx.doi.org/10.24327/ijcar.2017.3573.0317

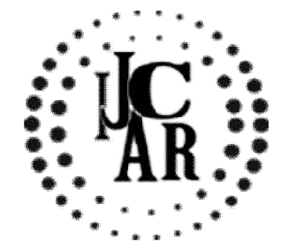

Research Article

\title{
COMPARATIVE EVALUATION OF THE EFFECT OF THREE DIFFERENT ATTACHMENT SYSTEMS ON STRESS DISTRIBUTION PATTERNS IN TWO IMPLANT SUPPORTED MAXILLARY OVERDENTURE: A 3D FINITE ELEMENT ANALYSIS
}

\section{Gade Jaykumar Rambhau., Khodaskar Neha Arun., Agrawal SonamVinod., GadeVandana Jaykumar and Lahoti Krishna kumar}

Department of Prosthodontics Swargiya Dadasaheb Kalmegh Smruti Dental College And Hospital, Hingna, Nagpur

\section{A R T I C L E I N F O}

\section{Article History:}

Received $7^{\text {th }}$ February, 2017

Received in revised form $12^{\text {th }}$ March, 2017

Accepted $15^{\text {th }}$ April, 2017

Published online $28^{\text {th }}$ May, 2017

\section{Key words:}

Ball attachment, Bar Attachment, Locator Attachment, Finite element analysis, Stress distribution.

\begin{abstract}
A B S T R A C T
Purpose: To evaluate and compare the stress distribution patterns on two implant supported maxillary overdenture with three different attachment systems using a 3D finite element analysis.

Material and methods: The 3D finite element models were prepared using maxillary two implant supported overdenture models with implants placed in canine regions bilaterally. Total three models using three different attachment systems namely Ball, Hader Bar and Locator attachments were used in this study. All the models were loaded bilaterally with an incremental vertical load from $0-100 \mathrm{~N}$ at increments of $0,20,40,60,80$ and $100 \mathrm{~N}$.

Results: In cortical bone the maximum von-mises stress of around 12.5 MPa is observed for Bar attachment design and the minimum von-mises stress of around $9.57 \mathrm{MPa}$ is observed for Locator attachment design. In the cancellous bone the maximum von-mises stress of around $3.26 \mathrm{MPa}$ is observed for Ball attachment design and the minimum vonmises stress of around 3.1 MPa is observed for Bar attachment design.

Conclusion: within the limitations of the study it was observed that in cortical bone maximum Von Mises stresses were observed for bar attachments and minimum for locator attachments. In cancellous bone maximum Von Mises stresses were observed for ball attachments and minimum for bar attachments.
\end{abstract}

Copyright $@ 2017$ Gade JaykumarRambhau et al. This is an open access article distributed under the Creative Commons Attribution License, which permits unrestricted use, distribution, and reproduction in any medium, provided the original work is properly cited.

\section{INTRODUCTION}

Implant retained overdenture are alternative treatment options because of their relative simplicity, minimal invasiveness and affordability especially for patients presenting persistent problems with conventional complete dentures. They are supported, retainedand stabilized by both implants and mucosa, therefore it requires fewer implant than fixed implant prosthesis. Palatal coverage and proper extension of the overdenture is necessary to transmit the loads to primary load bearing area in maxilla. Applications of attachments improve the retention of implant retained overdentures. If not chosen properly they transmit the horizontal or vertical load to supporting implants which may result in marginal bone resorption, periodontal bone loss, pressure necrosis and failure of osseointegration. So, stress around dental implant is analysed using several methods including Photoelasticity, Finite Element Analysis ${ }^{1}$, Strain gauges ${ }^{2}$ on bony surfaces. The advantages of Finite Element Analysis include accurate representing, complex geometries, easy model modification and representation of the internal stress ${ }^{1}$.

\section{*Corresponding author: Gade JaykumarRambhau} Department of Prosthodontics Swargiya Dadasaheb Kalmegh Smruti Dental College And Hospital, Hingna, Nagpur
Ideally 4-6 implants are indicated for maxillary implant supported overdentures ${ }^{3}$. Many patients may not be able to proceed with an ideal treatment plan due to concerns related to overall health and healing capacity or simply financial constraints. Thus two implant supported overdenture in maxilla appear to be better alternative.

Unlike, mandibular two implant supported overdenture there is very less documentation about maxillary two implant supported overdenture with different attachment systems. Thus aim of this study was to evaluate and compare the stress distribution patterns on two implant supported maxillary overdenture with three different attachment systems using a 3D finite element analysis. The objectives of study were: i) To evaluate stress distribution patterns of the two implant supported maxillary overdenture with Ball, Bar and locator attachments. ii) To compare the stress distribution patterns obtained with three different attachment systems.

\section{MATERIALS AND METHODS}

\section{Construction of finite element models}

A CT scan of maxilla was utilised to model the bone by plotting the key points on the graph and generating identical 
key points on the ANSYS 12.1 Software $^{4}$.The three $3 \mathrm{D}$ finite element maxillary two implant supported overdenture models with implants placed in canine regions bilaterally having three different attachment systems namely, Ball, Bar and Locator attachments were used in this study. These models were labelled as A, B, C respectively. (fig 1,2,3)

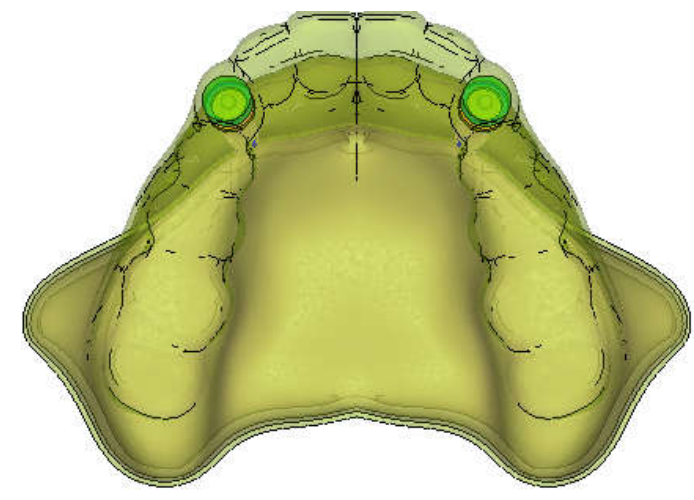

Figure 1 Model A-Ball Attachments

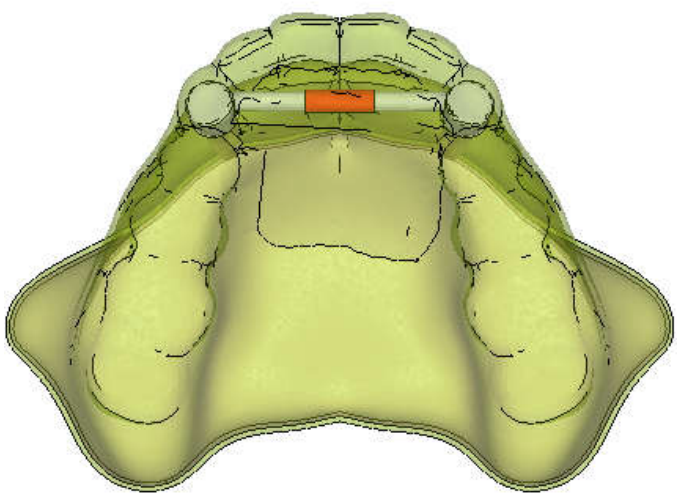

Figure 2 Model B- Bar Attachment

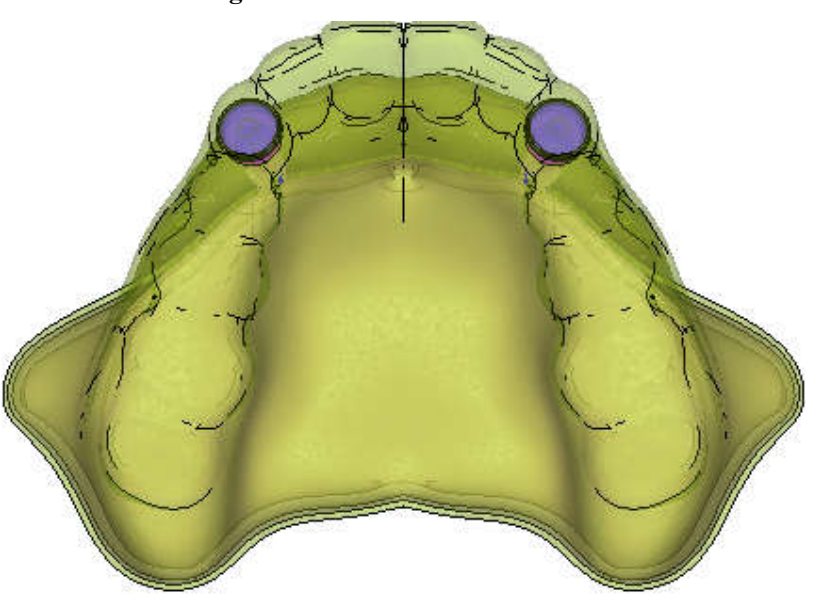

Figure 3 Model C- Locator Attachments

An implant having $3.75 \mathrm{~mm}$ diameter and length $11.5 \mathrm{~mm}$ (Noble Biocare) was modelled. The surface of simulated implant was threaded having thread pitch $0.4 \mathrm{~mm}$ and inner diameter of implant was $2.25 \mathrm{~mm}$.

The ball attachment modelled was $2.25 \mathrm{~mm}$ in diameter with cuff height $1 \mathrm{~mm}$ and overall length of $3 \mathrm{~mm}$ for model $\mathrm{A}$. The silicon O-ring attachment had an inner radius of $1.25 \mathrm{~mm}$ and outer radius of $2 \mathrm{~mm}$.

The bar attachment modelled was $25 \mathrm{~mm}$ in length for the model B. The locator attachment modelled was $3.86 \mathrm{~mm}$ in diameter with cuff height $1.78 \mathrm{~mm}$ and overall length $3.81 \mathrm{~mm}$ for the model $\mathrm{C}$.
The mucosa was modelled on the cortical bone having thickness of $2 \mathrm{~mm}$ all over. An overdenture having acrylic denture base and acrylic teeth was modelled over the implants with attachments on all three models. All these materials that were utilised in this model were regarded as homogeneous isotropic and linearly elastic.

\section{Meshing of the models}

A CT scan of a completely edentulous patient was procured and then only region of interest (maxilla) was considered and then converted the dicom data into geometric models using reverse engineering technique

The reverse engineering includes scanning the models, measuring the length, diameter and other features using standard measuring instruments and scanning machines. The Geometric modeling was done using "Rapid form" software (3D Systems Geometric, Korea). A"Hypermesh" meshing software (Hypermesh 13.0 Altair Engineering Inc.Hypermesh, America) was used for mesing of the geometric models of the edentulous maxilla, overdenture and implant abutment system. In hypermesh the individual parts like soft bone, hard bone, implant, attachment mucosa and denture were then discriticised and assembled. These meshed models are called finite element models and it consists of nodes and element data. Total no. of nodes and elements are listed in the table 1.

Table 1 Nodes and Elements

\begin{tabular}{ccc}
\hline Part & $\begin{array}{c}\text { No. of } \\
\text { Nodes }\end{array}$ & $\begin{array}{c}\text { No. Of } \\
\text { elements }\end{array}$ \\
\hline Cortical Bone & 23966 & 75184 \\
Cancellous bone & 35551 & 139992 \\
Mucosa & 21394 & 63519 \\
Implant & 19956 & 79504 \\
Ball attachment & 5212 & 17832 \\
Denture Cap & 1654 & 5426 \\
Rubber & 740 & 1830 \\
Clip & 530 & 1398 \\
Bar Attachment & 3728 & 11631 \\
Locator Attachment & 4254 & 15934 \\
Denture & 28122 & 91744 \\
\hline
\end{tabular}

\section{Loading procedure}

The three meshed models $\mathrm{A}, \mathrm{B}$ and $\mathrm{C}$ were afflicted by incremental loading force from $0-100 \mathrm{~N}$ at interval of $0,20,40,60,80$ and 100 for all three attachments.

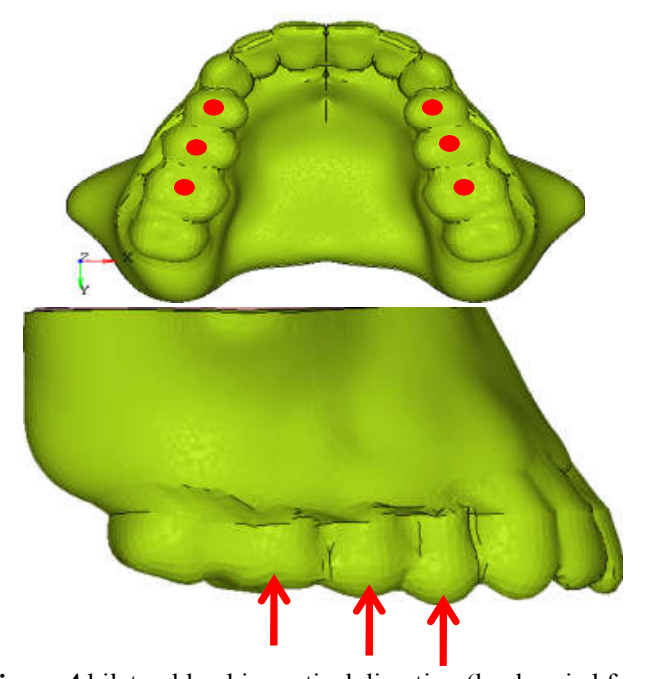

Figure 4 bilateral load in vertical direction (load varied from $0,20,40,60,80$ and $100 \mathrm{~N})$ 
The loading was done bilaterally in the region of first premolar, second premolar and first molar region (fig 4).

\section{RESULTS}

The 3D models of maxillary two implant supported overdenture with three different attachment systems of the maxilla comprising of cortical bone and cancellous bone was constructed. The vertical force ranging from $0-100 \mathrm{~N}$ was applied to the first premolar, second premolar and first molar area in increments $0,10,40,60,80$ and $100 \mathrm{~N}$. The stresses generated in both type of bone as well as implants with attachments were assessed.

\section{Following models were studied}

Model A: Two implant supported maxillary overdenture with ball attachment.

Model B: Two implant supported maxillary overdenture with bar attachment.

Model C: Two implant supported maxillary overdenture with locator attachment.

The material properties of various materials used in the model were taken from the literature ${ }^{5,6}$ (table 2).

Table 2 Mechanical properties of the materials

\begin{tabular}{|c|c|c|c|}
\hline $\begin{array}{l}\text { STRUCTURAL } \\
\text { ELEMENT }\end{array}$ & POISSON'S RATIO & $\begin{array}{l}\text { YOUNG'S } \\
\text { MODULUS }\end{array}$ & REFERENCES \\
\hline Cortical Bone & 0.3 & 13700 & Barbier et al \\
\hline Cancellous Bone & 0.3 & 1370 & Barbier et al \\
\hline Mucosa & 0.37 & 1 & Menicucci et al \\
\hline Acrylie Resin & 0.35 & 3000 & Tanino et al \\
\hline Acrylic Tooth & 0.35 & 3000 & Tanino et al \\
\hline Titanium & 0.3 & 135000 & Brunskiet al \\
\hline Co-Cr Alloy & 0.33 & 218000 & Caglar et al \\
\hline Stainless Steel & 0.31 & 19000 & Barao et al \\
\hline Plastic Clip & 0.28 & 3000 & Manufacturer \\
\hline O' Ring Rubber & 0.45 & 5 & Chun et al \\
\hline Nylon Cap & 0.45 & 5 & Chunet al \\
\hline
\end{tabular}

The Von-mises stresses and their distribution at the bone level and implant level was obtained through a finite element software and the data was in the form of colour coded graph. The stress graph had gradation of colour from red to blue, red colour indicated the highest stress area whereas blue was the lowest stress area.

Graph 1 shows that in cortical bone the maximum von-mises stress of around $12.5 \mathrm{MPa}$ is observed for Bar attachment design and the minimum von-mises stress of around $9.57 \mathrm{MPa}$ is observed for Locator attachment design.

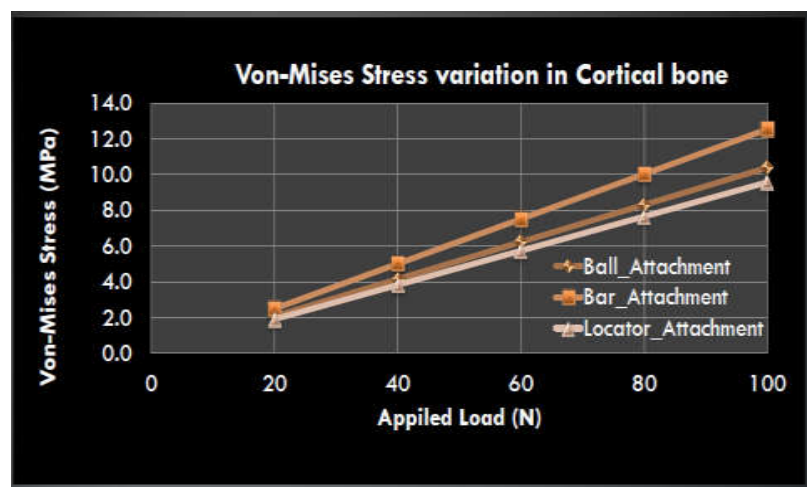

Graph 1 Von Mises Stresses in Cortical Bone
Graph 2 shows that in cancellous the maximum von-mises stress of around $3.26 \mathrm{MPa}$ is observed for Ball attachment design and the minimum von-mises stress of around 3.1 $\mathrm{MPa}$ is observed for Bar attachment design.

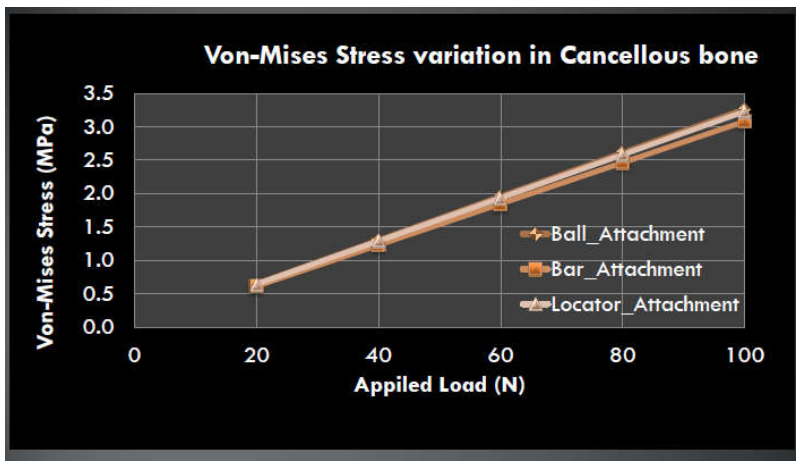

Graph 2 Von Mises Stresses in Cancellous bone

Graph 3 shows that at implant and attachment levelthe maximum von-mises stress of around $43 \mathrm{MPa}$ is observed for Bar attachment design whereas the minimum von-mises stress of around $38 \mathrm{MPa}$ is observed for Ball attachment design.

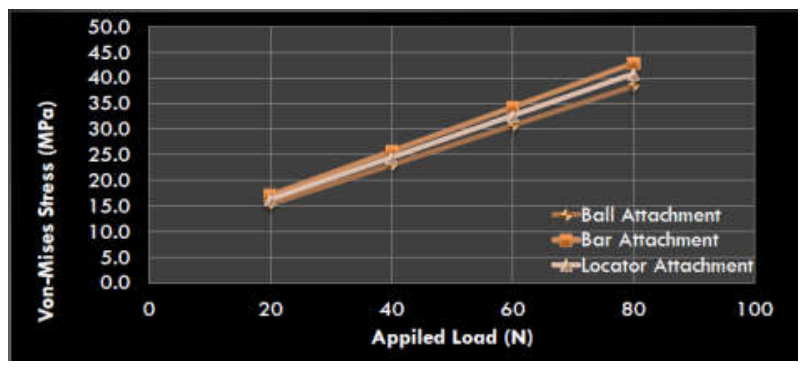

Graph 3 Von-mises Stress comparison in Implant Attachment Designs

Graph 4 shows that, the max stress in cortical bone is observed for Bar attachment design and minimum stress is observed with locator attachment design.

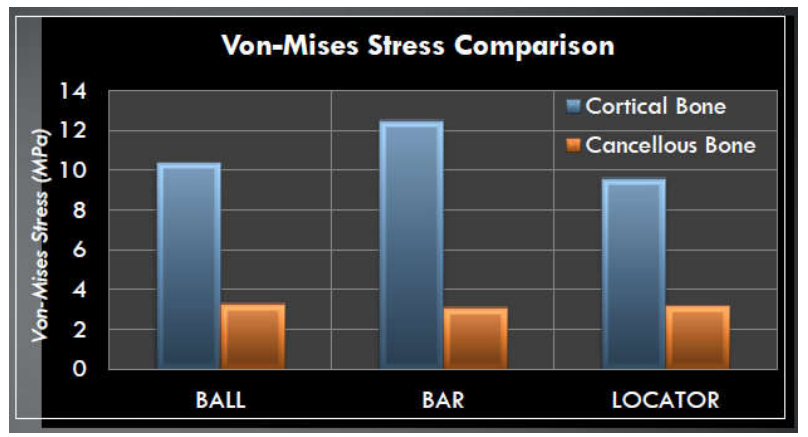

Graph 4 Von-Mises Stress Comparison between cortical and cancellous bone with different attachment systems.

Also for stresses in cancellous bone its almost same in all three cases. Since the minimum stress is observed on cortical bone with locator attachment design, it is the best design compared to other two designs for the applied load and assumed material properties.

\section{DISCUSSION}

An implant supported overdenture is subjected to various types of axial and non axial stresses. The resultant of these forces is transmitted through the superstructure and the attachments to the implants and may lead to concentration of stresses in different parts of implants as well as surrounding bone ${ }^{7,8,9}$. This study was conducted to evaluate stress patterns 
of maxillary two implant supported overdenture with three different attachments namely Ball, Bar and Locator attachments.

- $\quad$ Stress Distribution at the Cortical Bone Interface under vertical Loading. The maximum stress was found concentrated in model B (Hader bar) with vertical loading. The Minimum stress concentration was seen in model C (locator attachment).

- Stress Distribution at the Cancellous Bone Interface under vertical Loading Conditions. The maximum stress was found concentrated in model A (Ball attachment) with vertical loading. The minimum stress concentration was seen in model B (Hader Bar).

- Stress Distribution in the Implant Body under vertical Loading Conditions:

The maximum von-misesstress were observed for Bar attachment design.

The minimum von-misesstress were observed for Ball attachment design.

The results of this study indicates that stress distribution pattern differ under different bone conditions with different attachment systems.

\section{CONCLUSION}

Within the limitations of this study following conclusions were drawn:

1. In cortical bone maximum Von Mises stresses were observed for bar attachments and minimum Von Mises stresses were observed for locator attachments.

2. In cancellous bone maximum Von Mises stresses were observed for ball attachments and minimum Von Mises stresses were observed for bar attachments.

Thus it can be concluded that quality of bone influences the attachment selection.

\section{References}

1. Geng JP, Tan KB, Liu GR. Application of finite element analysis in implant dentistry: a review of the literature. The Journal of prosthetic dentistry. 2001 Jun 30; 85(6):585-98.

\section{How to cite this article:}

Gade Jaykumar Rambhau et al (2017) ' Comparative Evaluation Of The effect Of Three Different Attachment Systems On Stress Distribution Patterns In Two Implant Supported Maxillary Overdenture: A 3d Finite Element Analysis', International Journal of Current Advanced Research, 06(05), pp. 3570-3573.
2. Satpathy S, Babu CS, Shetty S, Raj B. Stress distribution patterns of implant supported overdentures-analog versus finite element analysis: A comparative in-vitro study. The Journal of Indian Prosthodontic Society. 2015 Jul 1; 15(3):250.

3. Damghani S, Masri R, Driscoll CF, Romberg E. The effect of number and distribution of unsplinted maxillary implants on the load transfer in implantretained maxillary overdentures: An in vitro study. The Journal of prosthetic dentistry. 2012 Jun 30; 107(6):358-65.

4. Kayabaşı O, Yüzbasığlu E, Erzincanlı F. Static, dynamic and fatigue behaviors of dental implant using finite element method. Advances in engineering software. 2006 Oct 31; 37(10):649-58.

5. Chun Hj, Park Dn, Han Ch, Heo Sj, Heo Ms, Koak JY. Stress distributions in maxillary bone surrounding overdenture implants with different overdenture attachments. Journal of oral rehabilitation. 2005 Mar 1; 32(3):193-205.

6. Kim MJ, Hong SO. Finite element analysis on stress distribution of maxillary implant-retained overdentures depending on the Bar attachment design and palatal coverage. The journal of advanced prosthodontics. 2016 Apr 1; 8(2):85-93.

7. Eskitascioglu G, Usumez A, Sevimay M, Soykan E, Unsal E. The influence of occlusal loading location on stresses transferred to implant-supported prostheses and supporting bone: a three-dimensional finite element study. The Journal of prosthetic dentistry. 2004 Feb 29; 91(2):144-50.

8. Sevimay M, Turhan F, Kiliçarslan MA, Eskitascioglu G. Three-dimensional finite element analysis of the effect of different bone quality on stress distribution in an implant-supported crown. The Journal of prosthetic dentistry. 2005 Mar 31; 93(3):227-34.

9. Şahin S, Cehreli MC, Yalçın E. The influence of functional forces on the biomechanics of implantsupported prostheses-a review. Journal of dentistry. 2002 Nov 30;30(7):271-82 